\title{
Knowledge Management for Banking Industry Continuous Improvement
}

\author{
Maya Irjayantia*, Anton Mulyono Azis ${ }^{\mathrm{a}}$ \\ ${ }^{a}$ STIE Ekuitas, P.H.H Mustopa 31 Bandung, Indonesia \\ *Corresponding author: m.irjayanti@gmail.com
}

\section{Article history}

Received :4 April 2013

Received in revised form : 25 July 2013

Accepted :15 October 2013

\begin{abstract}
Knowledge Management (KM) provides formal activity so the industry could implement to prevent knowledge lost. Subsequently, KM plays important role to manage the intellectual capital for maintaining industrial sustainability. Finally, increases the performance through saving all tacit knowledge from their potential workers. Especially in service industry like banking, where most knowledge obtained from experience while serving clients, to achieve its best performance, service industry should put KM as a standard. Since most KM starts from identify tacit knowledge, service industry must create certain process to transfer it as an explicit knowledge. This research aim to build $\mathrm{KM}$ system not only to transform tacit into explicit knowledge, but also to prevent important knowledge lost. The method used in this research were divided into three sections: literature review, study the standard of creating KM process, and synthesis process in knowledge management as a preliminary model. Based on the result, KM system consists certain formal activities like building managerial commitment, creating KM division, socializing KM, sharing, documenting, and implementing the knowledge. The results expected is a valuable contribution to secure employees' tacit knowledge through building of Standard Operating Procedure for KM, so the company could perform with certain standard without rely on certain employees ability.
\end{abstract}

Keywords : Knowledge management; banking industry

(C) 2013 Penerbit UTM Press. All rights reserved.

\subsection{INTRODUCTION}

Many studies acknowledge that now the world is undergoing a global shift towards a knowledge-focused economy. Walczak (2005) stated that the worldwide economy has shifted from an industrial manufacturing/product orientated economy to one based on knowledge and services, where the principle commodity is information or knowledge. Supported by Lim et al. (1999) that the importance of knowledge management is being realised and identified as the critical success factor for today's businesses. Knowledge Management (KM) is necessary to prevent a potential lost of knowledge due to the discontinuation because of retirement and employee's turnover. The importance of KM much motivated by variety of phenomena, for instances, large numbers of retirement without any successors, potential human resources that move out of the industry and bring their important knowledge, low ability of innovation capability because of knowledge lost (Portalhr, 2012).

Moreover lacks of knowledge transfer practices create the condition where growing knowledge and learning only belong to certain people, such as researchers and practitioners (Pnri, 2012) and even several success factors of entrepreneur just only known by him/her self, and usually lack the process of knowledge transfer (Irjayanti and Azis, 2012a). Related to that, KM which relate with information, policies and data involving all aspects of the organizations must be managed properly. So, this become crucial to strengthen the role of KM to deal with the information, especially to minimize the loss of knowledge that is essential for industry survival.

Subsequently KM plays important role to manage the intellectual capital for maintaining industrial sustainability. Shiong et al (2009) found that current learning approaches have various structured learning activities as well moreself-directed learning tasks. While, Intellectual capital synonymously used to refer to intangible assets and to knowledge capital and become the driver of value in an organization, it even could increases the performance through saving all tacit knowledge from their potential workers. Lin and Tseng (2005), stated that tacit knowledge is not as tangible and is more difficult to formalize or articulate as it generally is knowledge that is stored within an individual and as such is personal and context specific. Walczak (2005) explained this type of knowledge includes cognitive learning, mental models, and technical skills. Based on the importances, this paper is address what should industry through to build KM system, and how this system could be built.

\subsection{KNOWLEDGE MANAGEMENT CONCEPT}

$\mathrm{KM}$ is a process that helps in finding, selecting, disseminate and transfer important information and expertise someone for activities such as problem solving, dynamic learning, strategic 
planning, and decision making. KM is closely associated with the process of how the knowledge is created, shared and used to achieve a specific outcome such as shared knowledge, a higher level of innovation, or competitive advantage. KM conducted in Knowledge Management System (KMS) which used three approaches: people, process, and technology (Tjakraatmadja \& Lantu, 2006).

Prieto and Revilla (2006) explained the importance of both knowledge resources and learning processes to overall business performance improvement. The knowledge-based view of the firm, which emerges as an extension of the resource-based view of the firm, argues that heterogeneous knowledge bases among firms, and the ability to create and apply knowledge, are the main determinants of performance differences (Grant, 1996; Spender, 1996; Decarolis and Deeds, 1999). Followed by Lee and Steen (2006) who stated that know-how is a key resource for business, and know-how management a potential lever for competitive advantage. Tacit knowledge is generally referred in the literature as the know-how that individuals possess within themselves and as such cannot be easily shared or documented like explicit knowledge.

Knowledge Management provides formal activity so the industry could implement to prevent knowledge lost. Waddel and Stewart (2008) agreed that there are a relationship between knowledge management and quality management; paying particular attention to how knowledge management and quality management can be managed to assist the development of a quality culture. Gloet and Berrell, 2003; Lee and Yang, 2000; Prasad, 2001 found that knowledge management can contribute to their significant aspects, but most importantly they see knowledge management as a way of providing competitive advantage. As also mentioned by Irjayanti and Azis (2012b) competition in international markets depends on competitive advantage, and it can create by knowing the substance aspect that set in individual and organizational knowledge.

Moreover, Baharun and Salleh (2007) agreed that identifying of profile and banking habits as well as their awareness, usage, is important to influence degree of satisfaction, included factors of determining customers like friendliness of bank personnel and caring attitude toward customers. Consequently, to get a good performance and continuous improvement, industry should put $\mathrm{KM}$ as a standard (See figure 1). Since most KM starts from identified tacit knowledge, industry must create certain process to transfer it as an explicit knowledge. This valuable tacit knowledge mostly owned by person who overcomes his job for long time, where he gathered his knowledge through experience, creativity, or social networking. Essentially, implementing KM is how the industry could identify tacit knowledge and what form of procedure should be built to translate tacit knowledge into explicit knowledge successfully. The entire knowledge that have been identified and documented in various accessible form become a foundation for doing better work procedures for other employees who will occupy the same position, it could create a better work performance every time for person who will work in that position. With the continuation of this pattern, it will directly affect the industry performance continuously.

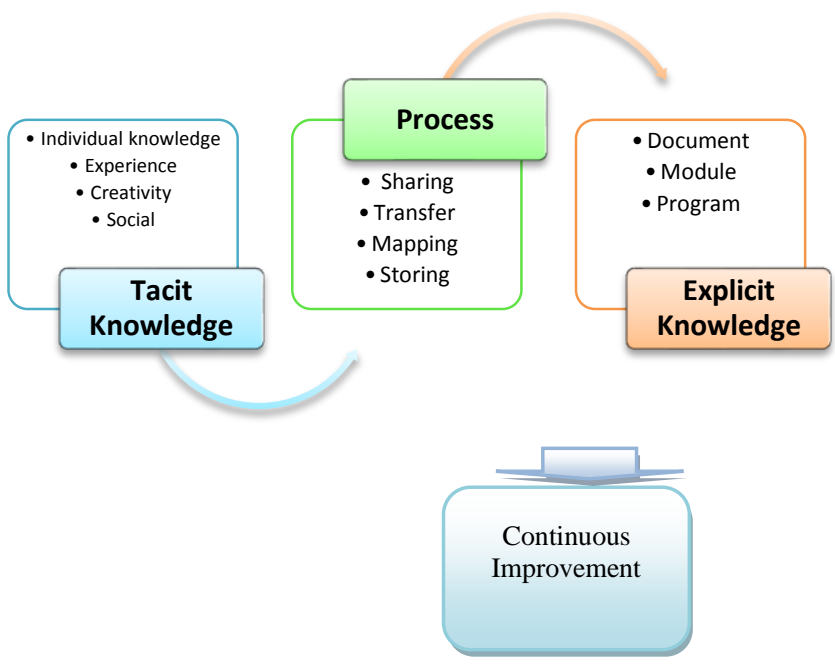

Figure 1 theoretical framework

\subsection{RESEARCH METHODOLOGY}

In creating $\mathrm{KM}$ process this study consists of three sections:1) literature review: materials and research report on knowledge management field, 2) study the standard of creating KM process adapted from various research, 3) synthesis process in knowledge management as a preliminary model. The establishment of KM system through collecting the main process should be followed by managerial level of organizations in the service industry. Service industries have been chosen because of their importance in the global economy. In Indonesia, most workforce is involved in services (Manning and Aswicahyono,2012). In addition, this research is also designed to determine the participants' knowledge of these indicators and to assess their understanding of how their measurement is conducted. The strategic implications of understanding the indicators are also discussed within the context of the attitude of top management.

The research was conducted primarily through qualitative research with selected participants who were keen to discuss further the implications of this research. This study was carried out with five respondents of Indonesian banking industries with at least 10 years sustainability. The participants were based in their head offices as the representatives of the head of divisions or functions in Bandung, West Java, Indonesia. The prospective were asked to indicate their perceived importance to disclose the $\mathrm{KM}$ system and to identify their level of understanding on how KM should be proceed.

\subsection{RESULTS AND DISCUSSION}

The effectiveness of $\mathrm{KM}$ processes to grow and maintain intellectual capital depends on their match with the organizational requirements. One of the key criteria for effective knowledge management processes seems to be the match with the organizational objectives. Nonaka and Toyama (2005) stated that creating knowledge organizationally does not just mean organizational members supplementing each other to overcome an individual's bounded rationality. Knowledge is socially created through the synthesis of the different views held by various people. Through the knowledge conversion process socialization, externalization, combination, and internalization (SECI) process, 
personal subjective knowledge is validated socially and synthesized with others' knowledge so that knowledge keeps expanding. Subjective tacit knowledge held by an individual should be externalized into objective explicit knowledge to be shared and synthesized.

Lyons et al (2008) stated that KM practices also are a crucial component of continuous performance improvement (CPI) model, which embeds processes for learning before, during, and after execution into the way teams plan, execute, and assess their performance. Making these learning processes part of the way we work allows teams to finalize their project plans based on the "latest and greatest" corporate know-how, assess ongoing performance to reinforce positive patterns or make immediate course corrections, and reflect after execution to identify learnings and advice that can be shared and reused across the organization. Table 1. shows various KM practices in industry with each element used to create the process.

Table 1 Knowledge management practices

\begin{tabular}{|c|c|c|}
\hline Model & Stages & Sources \\
\hline Knowledge-creating firm & $\begin{array}{l}\text { 1. Socialization, Externalization, Combination, and Internalization } \\
\text { (SECI) process of dialogues and practice } \\
\text { 2. Share nowledge vision and driving objective } \\
\text { 3. Managing knowledge assets } \\
\text { 4. Creating the environment as an ecosystem of knowledge. }\end{array}$ & $\begin{array}{l}\text { Nonaka and } \\
\text { Toyama (2005) }\end{array}$ \\
\hline Intangible Assets & $\begin{array}{l}\text { 1. Commitment to the improvement } \\
\text { 2. Measure benefits arising from an intangible investment; } \\
\text { 3. Commit to the development. } \\
\text { 4. Improve corporate governance mechanisms } \\
\text { 5. Build the integration and uniting of all projects }\end{array}$ & Garcia (2003) \\
\hline $\begin{array}{l}\text { Intellectual Capital (IC) } \\
\text { Management }\end{array}$ & $\begin{array}{l}\text { 1. Identifying key IC } \\
\text { 2. Visualizing the value creation path ways and transformations of the } \\
\text { key IC } \\
\text { 3. Measuring performance in particular dynamic transformations } \\
\text { 4. Cultivating the key IC } \\
\text { 5. Internal and external reporting of performance }\end{array}$ & Marr et al (2003) \\
\hline Learning Capability & $\begin{array}{l}\text { 1. Collect knowledge stocks } \\
\text { 2. Gather Individual-level knowledge, Group-level knowledge, } \\
\text { Organizational-level knowledge } \\
\text { 3. Create learning flows } \\
\text { 4. Doing Exploration and Exploitation }\end{array}$ & $\begin{array}{l}\text { Prieto and Revilla } \\
\text { (2006) }\end{array}$ \\
\hline
\end{tabular}

Table 1 illustrates the various models for building KM. Nonaka and Toyama (2005) build a knowledge-creating firm through SECI process through dialogue, sharing, managing knowledge assets, and creating an environment that supports a culture of knowledge management. While Garcia (2003), managing intangible assets begins with creating a commitment to make improvements of intangible investment corporate governance mechanisms. Another model from Marr et al. (2003) on Intellectual Capital (IC) management, she began the process by identifying key IC, visualizing the value creation path ways and transformations of the key ICs, and Measuring performance in particular dynamic transformations. The last, a model from Prieto and Revilla (2006) through the learning capability, the company should start KM with gathering knowledge stocks, gathering Individual-level knowledge, Group-level knowledge, Organizational-level knowledge, creating learning flows, and doing Exploration and Exploitation.

Those models are the foundation for the new KM modeling in this study using all elements mentioned. KM model built also consist activities like making a commitment, creating standards/procedures, identifying intellectual capital/knowledge assets, transforming it into explicit knowledge, documenting, and implementing the knowledge invented improvements continuously for better performance.

To build the KM system, based on literature reviews, this study collected essential components that mentioned in various literature, and put the whole component in survey form that were spreaded to respondents, to see how this model could be implemented in their service industry. The respondents manage the KM component and compiled them into sequence activities like shown at figure 2 .

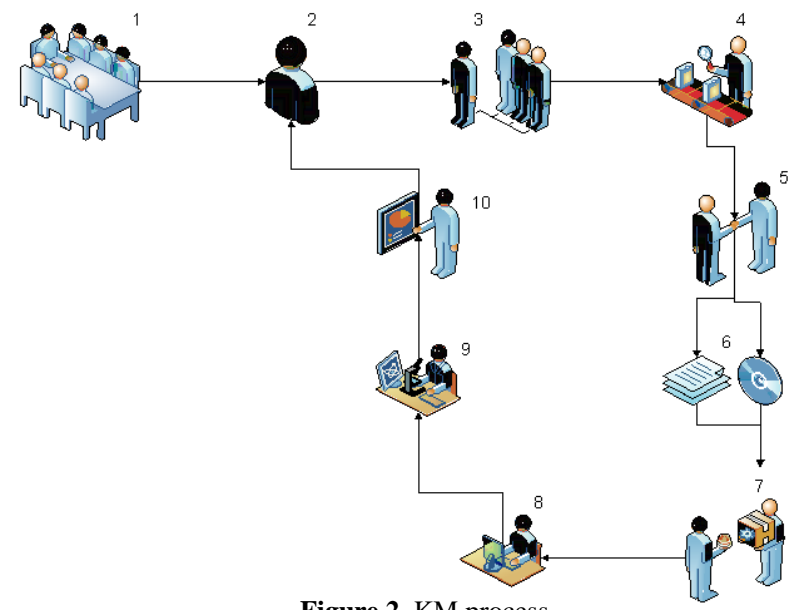

Figure $2 \mathrm{KM}$ process 
Respondents agreed that to build KM system, industry must begin with strong commitment from all managerial levels, it is absolutely necessary for the application of $\mathrm{KM}$ to prevent knowledge lost. Groups in the industry interact and communicate their knowledge to other groups, and acquire from them knowledge required to put their own knowledge into action (Prieto and Revilla, 2006). Intellectual capital of industry, which is owned by employees, made them assets for the industry. Having knowledge about their clients characters, or the most effective and efficient ways to finish one job, leave the industry open to serious problem if they leave the industry, bring their tacit knowledge, and share their loyalties with competing industry. Choo and Bontis (2002), said that human capital is the cumulative tacit knowledge of employees within a firm. Hudson (1993) found that human capital could be gained through several factors like genetic inheritance, education, experience, and attitude about life and business. The essesce of human capital is the individual intellect of the employee and is therefore a function of the employee's ability to thrive within the industry (Stovel and Bontis, 2002).

In banking industry, most of knowledge is tacit knowledge which is independently developed by employees through daily interactions with clients. That is the reason why turnover is relatively high in this industry, hijacking activities is happened due to the valuable tacit knowledge. In banking industry, the knowledge of process, client character, habits becomes the key to success in banking performance.

In figure 2, the first step to build $\mathrm{KM}$ is ensure the commitment among the managerial level to emphasize the importance of managing KM. All managers are expected to contribute their thoughts on how knowledge can be extracted and identified from the employee, with proper approach to prevent any offending among employees. At this meeting, also discussed the process of documentation and utilization of documented knowledge. The results of this meeting is creating SOP to start KM with reward system to appreciate the value of knowledge itself. But what kind of knowledge that could be an asset for industry? Marr et al (2004) identified knowledge assets from various sources inside industry in figure 3 .

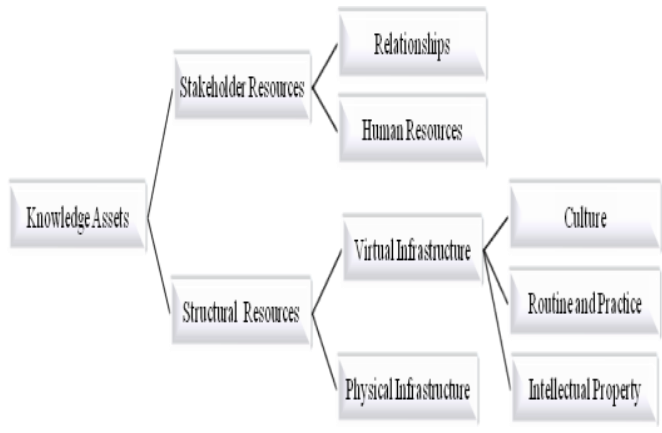

Figure 3 Knowledge assets (Marr et al., 2004)

Marr et al. (2004) found that in order to execute a successful strategy, industry need to know what their competitive advantage is and what capabilities they need to grow and maintain this advantage. Industries that seek to improve their capabilities need to identify and manage their knowledge assets.

Generally, all managerial levels create an agreement through planned meetings to discuss the KM importance. In that case, the industry appoints a manager that responsible for KM department to socialize the KM activities into all division and their human resources so they could start to identify the essential knowledge for industrial survival. This phase can be prepared through bringing potential people in strategic areas based on their personal knowledge, experience on the position, or social relationships approach. Social approach plays necessary role to ensure that people who invent the knowledge will not lose their intellectual rights, therefore, the industry should also prepare a Standard Operating Procedure (SOP) which consist reward mechanism for documenting tacit knowledge becomes explicit knowledge.

Entire tacit knowledge processes are documented through interviews; experiences sharing; knowledge transferring; mapping; and storing knowledge potential. The documents filed in hardcopy and softcopy in each department for successor guideline. The entire stored knowledge archive becomes the foundation for building a standard operating procedure that is able to be used by next successor who works in the same position. Person with the knowledge is obligated to guide other people in his department or guide his replacement (if he retire or move to another department) with the knowledge standards that had been discovered. Successor who replaced previous manager will likely find new tacit knowledge during his job, and somehow the tacit knowledge invented even better than before. In this condition, SOP of KM plays its role, the manager must inform the knowledge to the KM Manager to start the series of $\mathrm{KM}$ process and continue the whole process for continuous improvement.

Since the KM SOP also contains reward elements for tacit knowledge, people will consider it as valuable asset, so it can stimulate employee creativity to find better method working their job. Employees who occupy a new position, will constantly be challenged to find ways and to manage new client, because they assume that knowledge will be extremely valuable to industry performance. They will be more proactive in seeking information, create simulations, trying new methods, which are considered to be a better process than prior knowledge. In the end, the result of this process is not only valuable for the individuals themselves, but also for the performance of the industry as a whole.

\subsection{CONCLUSION}

Basically, to build KM system in service industry, all managerial levels/groups should have strong commitment about the importance of protect intellectual capital especially tacit knowledge. That becomes the beginning step to create KM division with responsible manager to ensure that KM starts as formal procedure. First, KM should be disseminated to the entire industry, KM manager has the overall responsibility to ensure that employees follow those procedures. Then, identify the knowledge that are important to the industry, to be informed and documented so it could be the basis for working procedures in certain positions.

Social approach plays necessary role to ensure that people who invent the knowledge will not lose their intellectual rights, therefore, the industry should also prepare a Standard Operating Procedure (SOP) which consist reward mechanism for documenting tacit knowledge becomes explicit knowledge. Successor who replaced previous manager will likely find new tacit knowledge during his job, and somehow the tacit knowledge invented even better than before. In this condition, SOP of KM plays its role, the manager must inform the knowledge to the KM Manager to start the series of KM process and continue the whole process for continuous improvement. 
Hopefully, this finding become a foundation for future research to see how this model could implement in different industries, and see how it is really worked significantly for the industrial performance improvement.

\section{References}

[1] Baharun, R and Salleh, N, M. D. 2007. Retail Banking: A Study Of Bank Selection Criteria In Malaysia's Islamic Banking Service. Jurnal Teknologi. 47(E): 1-14.

[2] Choo, C. W. and Bontis, N. 2002. The Strategic Management of Intellectual Capital and Organizational Knowledge. Oxford University Press. New York. NY.

[3] Garcia, A. M. 2003. Intangibles: Lessons from the Past and a look into the Future. Journal of Intellectual Capital. 4(4): 593-600.

[4] Gloet, M. and Berrell, M. 2003. The Dual Paradigm Nature of Knowledge Management: Implications for Achieving Quality Outcomes in Human Resource Management. Journal of Knowledge Management. 7(1): 78-89.

[5] Grant, R. M. 1996. Prospering in Dynamically-Competitive Environments: Organizational Capability as Knowledge Integration. Organization Science. 7(4): 375-387.

[6] Hudson, W. I. 1993. Intellectual Capital. John Wiley \& Sons. New York, NY.

17] Irjayanti, M. and Azis, A. M. 2012a. Barrier Factors and Potentia Solutions for Indonesian SMEs. Procedia Economics and Finance. 4 3-12.

[8] Irjayanti, M. and Azis, A. M. 2012b. Success Factors of Fast Moving Goods of Small Medium Enterprises In Indonesia. Proceeding at $2^{\text {nd }}$ Annual Summit on Business and Entrepreneurial Studies. October $15^{\text {th }}$ $16^{\text {th }}, 2012$.

[9] Lee, D and Van den Steen, E. 2006. Managing Know-How. Working Paper.

[10] Lee, C. C. and Yang, J. 2000. Knowledge Value Chain. Journal of Management Development. 19(9): 783-93.

[11] Lim, K. K., Ahmed, P. K. and Zairi, M. 1999. Managing for Quality Through Knowledge Management. Total Quality Management. 10(4) 615-621.

[12] Lin, C. and Tseng, S. 2005. The Implementation Gaps for the Knowledge Management System. Industrial Management \& Data Systems. 105(2): 208-22.
[13] Lyons, K., Acsente, D., and Waesberghe, M. 2008. Management and Quality Management to Sustain Knowledge Enabled Excellence in Performance. The Journal of Information and Knowledge Management Systems. 38(2): 241-253.

[14] Manning, C and Aswicahyono, H. 2012. Available at http:// www.ilo.org/ wcmsp5/ groups/public/---asia/---ro-bangkok/---ilojakarta/documents/publication/ wcms_185239. pdf accessed October 2012.

[15] Marr, B., Gupta, O., Pike, S., Ross, G. 2003. Intellectual Capital and Knowledge Management Effectiveness. Management Decision. 41(8): 771-781.

[16] Marr, B., Schiuma, G., Neely, A. 2004. Intellectual Capital - Defining Key Performance Indicators for Organisational Knowledge Assets. Business Process Management Journal. 10(5): 551-569.

17] Nonaka, I and Toyama, R. 2005. The Theory of The KnowledgeCreating Firm: Subjectivity, Objectivity and Synthesis. Industrial and Corporate Change. 14(3): 419-436.

[18] Pnri. 2012. Available at http://www.pnri.go.id/MajalahOnline Add.aspx?id=10. Accessed October 2012.

[19] Portalhr. 2012. Available at http://www.portalhr.com/berita/ meningkatkan-kinerja-dan-nilai-perusahaan-dengan-knowledgemanagement/. October November 2012

20] Prasad, B. 2001. Total Value Management-A Knowledge Managemen Concept for Integrating TQM into Concurrent Product and Process Development. Knowledge and Process Management. 8(2): 105-122.

[21] Prieto, I. M. and Revilla, E. 2006. Learning Capability and Business Performance: A Non-Financial and Financial Assessment. The Learning Organization. 13(2): 166-185.

[22] Shiong, K. B., Aris, B., and Tasir, Z. 2009. The Level Of Self-Directed Learning Among Teacher Training Institute Students-An Early Survey Jurnal Teknologi. 50(E) Jun 2009: 101-111.

[23] Spender, J. C. 1996. Making Knowledge the Basis of A Dynamic Theory of The Firm. Strategic Management Journal. 17: 45-62.

[24] Stovel, M. and Bontis, N. 2002. Voluntary Turnover: Knowledge Management - Friend or Foe? Journal of Intellectual Capital. 3(3) 303-322.

[25] Tjakraatmadja, J. H and Lantu, D. C. 2006. Knowledge Management. Bandung: Institut Teknologi Bandung.

[26] Waddel, D and Stewart, D. 2008. Knowledge management as perceived by quality practitioners. The TQM Journal. 20(1): 31-44.

[27] Walczak, S. 2005. Organisational Knowledge Management Structure The Learning Organisation. 12(4): 330-339. 